\section{POLÍTICA DE INOVAÇÃO NAS UNIVERSIDADES FEDERAIS DO NORDESTE: REFLEXOS DA IMPLEMENTAÇÃO DOS NITS POR MEIO DA LEI DE INOVAÇÃO}

\section{INOVVATION POLICY IN NORTHERN FEDERAL UNIVERSITIES: REFLECTIONS OF NITS IMPLAMENTATION FROM THE INNOVATION LAW}

\section{RESUMO}

A criação e a inovação acompanham a humanidade desde seus primórdios, e a preocupação em proteger essas descobertas é bem mais recente. Este artigo analisa o desenvolvimento da política de inovação nas universidades federais nordestinas por meio da Lei de Inovação, abordando o processo de institucionalização dos NITs. A pesquisa é descritiva, documental e bibliográfica, com a coleta dos dados centrada na identificação dos elementos elencados na lei de inovação nas instituições pesquisadas. O estudo revelou uma crescente mobilização das instituições na implementação das estruturas referentes à inovação prevista em instrumentos legais, porém com atuação ainda limitada a registro de patentes, seguindo normatização do INPI. Embora implantados, os NITs revelam iniciativas ainda incipientes de promoção da inovação. Esse avanço lento pode ser associado à necessidade de atualização da lei de inovação, representada pelo Marco Legal, em que se modificou grande parte da redação da lei de forma a torná-la mais clara e operacional.

Diana Beatriz Almeida dianabeatrizalmeida@gmail.com Mestranda em Propriedade Intelectual e Transferência de Tecnologias para Inovação pela Universidade Federal do Piaui. Teresina $-P I-B R$.

Helano Diógenes Pinheiro helanodp22@gmail.com Doutor em Administração. Professor do curso de Administração da Universidade Estadual do Piauí. Teresina$P I-B R$.
Palavras-chave: Inovação. NIT. Universidades Federais do Nordeste. Lei de Inovação.

\begin{abstract}
Creation and innovation have accompanied humanity since its beginnings, and the concern to protect these discoveries is much more recent. This article analyzes the development of the innovation policy in the Northeastern federal universities through the Law of Innovation, addressing the process of institutionalization of the NITs. The research is descriptive, documental and bibliographic, with the
\end{abstract}


collection of data focused on the identification of the elements listed in the innovation law in the researched institutions. The study revealed a growing mobilization of the institutions in the implementation of the structures related to innovation foreseen in legal instruments, but with performance still limited to the registration of patents, following INPI normalization. Although implemented, the NITs reveal still incipient initiatives to promote innovation. This slow progress may be associated with the need to update the innovation law, represented by the Legal Framework, in which much of the wording of the law has been modified in order to make it clearer and more operational.

Keywords: Innovation. NIT. Federal Universities of the Northeast. Innovation Law.

\section{INTRODUÇÃO}

A criação e a inovação são fenômenos que acompanham a humanidade desde seus primórdios, e a preocupação em proteger essas descobertas é bem mais recente. Com a sociedade do conhecimento (DRUCKER, 1987), o fruto da imaginação humana tornou-se o grande motor do desenvolvimento da sociedade. A capacidade humana de moldar a natureza amplia-se a cada geração. Em grande parte, esse acelerado processo de inovação humana é associado à proteção que os indivíduos passaram a ter de suas invenções. Desfrutar de proteção legal fornece aos indivíduos e às organizações certa segurança de que seus esforços não serão apropriados por terceiros.

Desde 2004, definiram-se regras e medidas que reforçam a necessidade de as Instituições de Ciência e Tecnologia (ICTs) estabelecerem e reforçarem suas políticas de inovação, centrando-se na criação de um mecanismo legal para gerir a inovação nas ICTs, que são os Núcleos de Inovação Tecnológica (NITs), que passam a atuar como um conselheiro das políticas de inovação das ICTs, por meio da Lei de Inovação e de suas regulamentações (KLEBIS, 2016).
Muitas instituições já possuíam órgãos responsáveis pela implementação dos aspectos definidos pela lei de inovação, sendo necessário apenas adequar-se à nomenclatura. Nas demais instituições, o processo de criação de NITs se acelerou a partir de 2008, sem clareza sobre formas de institucionalização, na medida em que sua atuação precisa propiciar um ambiente favorável à transferência de tecnologia e à proteção do conhecimento, os NITs atuam como interlocutores com o setor privado (MACHADO; SARTORI; CRUBELLATE, 2017). Ou seja, muitas instituições não tinham o conhecimento legal ou as condições institucionais para implementar. Dúvidas sobre o que fazer e como fazer permanecem. Nesse sentido, é importante estudar como as Instituições de Ciência e Tecnologia no Nordeste estão desenvolvendo suas estruturas e ações de gestão de sua propriedade intelectual.

Mesmo com a legislação, a criação dos NITs e dos diversos mecanismos de estímulo ao engajamento de entes públicos em atividades de inovação com empresas, ainda não é suficiente para um efetivo instrumento promotor (MACHADO; SARTORI; CRUBELLATE, 2017); em parte, devido à falta de compreensão de seus mecanismos bem como de questionamentos acerca de sua implementação nas ICTs. Salientando-se, ainda, que diferentes áreas de pesquisa possuem maior ou menor propensão a utilizar-se dos instrumentos de promoção da inovação (IPIRANGA; ALMEIDA, 2012).

As discrepâncias na implementação desses instrumentos legais nas ICTs revelam fatores maiores do que o simples desconhecimento ou a falta de estrutura; pois, enquanto algumas ICTs se tornam centros de excelência internacional, outras permanecem em estágio embrionário. Dessa forma, considerando o período coberto pela Lei de Inovação e pelo novo Marco Legal da Ciência e Tecnologia, é importante identificar como as ICTs incorporam os elementos legais de proteção de sua propriedade intelectual e de transferência do conhecimento para os meios produtivos.

Buscas realizadas em bases de dados re- 
velaram poucas publicações sobre a temática, como a busca por assunto no periódico Capes pelo termo "Núcleo de Inovação Tecnológica", no período 2010 a 2019, em qualquer lugar do artigo, retornou 38 resultados. Embora exista uma discussão sendo realizada sobre a promoção da inovação nas universidades, deve-se considerar a posição do Brasil quando comparada a outras economias mundiais, em que fica nas últimas posições quando se consideram patentes e transferência de tecnologia (CNI, 2020).

Considerando-se a inovação como o grande fator competitivo nas organizações do século XXI e o papel da universidade na geração de tecnologia e empreendimentos inovadores com base no conhecimento, exigem um reposicionamento da universidade nos processos de interação com a indústria (ETZKOWITZ; ZHOU, 2017). Como salientado acima, esse novo protagonismo das universidades se dará por meio da transformação de conhecimento em inovação, missão atribuída aos NITs, motivo pelo qual esses órgãos fornecem um bom panorama para se estudar o engajamento da instituição na promoção da inovação.

Para desenvolver a presente pesquisa, formulou-se o seguinte problema: Como as Instituições de Ciência e Tecnologia no Nordeste do Brasil estão incorporando a gestão da propriedade intelectual? E para responder a tal questão, a definição da região Nordeste foi escolhida para delimitar a pesquisa, tornando-a mais exequível.

Assim, este artigo define como objetivo analisar o desenvolvimento da política de inovação nas universidades federais nordestinas por meio da Lei de Inovação. O recorte geográfico foi definido para permitir uma análise mais homogênea e evidenciar a evolução de uma região em posição intermediária no sistema de ciência e tecnologia brasileiro. Quanto a serem universidades federais, ocorreu pelo maior grau de maturidade, em conjunto, na geração de pesquisa científica quando comparado com as IES estaduais e privadas da região.

$\mathrm{O}$ artigo inicia-se com uma revisão da literatura com três subseções, abordando a legislação da inovação no Brasil e caracterizando as ICTs e os Núcleos de Transferência de tecnologia. Na metodologia, identifica-se a pesquisa feita por meio de dados secundários e do registro de produção intelectual das instituições em estudo, os quais são discutidos na seção de resultados.

\section{REVISÃO DA LITERATURA}

\subsection{LEGISLAÇÃO BRASILEIRA DE INOVAÇÃO}

Em 28 de abril de 1809, o Brasil teve a sua primeira lei de patentes, por meio de um alvará de D. João VI, tornando-se uma das quatro primeiras nações, no mundo, a ter uma legislação de patentes. O objetivo era criar um sistema de incentivos ao desenvolvimento da tecnologia por meio de patentes industriais de concessão prevista em lei, em substituição ao sistema de privilégios individualizados, para atrair novas indústrias para o país.

Porém, apenas em 1945, obteve-se o primeiro Código de Propriedade Industrial, Dec. Lei 7.903/45, cuja elaboração, segundo Barbosa (2003), demonstrava sofisticação técnica infinitamente maior do que toda a legislação anterior. Esse código subsistiu por mais de meio século até o início da vigência do novo Código de 1996. Devido à pressão exercida pelo Governo dos Estados Unidos, a datar de 1987, com sanções unilaterais impostas sob a Seção 301 Trade Act., começou-se a origem do processo de mudança da Lei de Propriedade Industrial. Contudo, apenas em 14 de maio de 1996, sob o governo de Collor de Melo, foi promulgada a nova Lei de Propriedade Industrial, $\mathrm{N}^{\circ} 9.279 / 96$.

Essa lei regula direitos e obrigações relativos à propriedade industrial. Segundo seu Art. $2^{\circ}$, a proteção dos direitos relativos à propriedade industrial, considerando o seu interesse social e o desenvolvimento tecnológico e econômico do País, efetua-se mediante: 
I - concessão de patentes de invenção e de modelo de utilidade; II - concessão de registro de desenho industrial; III - concessão de registro de marca; IV - repressão às falsas indicações geográficas; e V - repressão à concorrência desleal. Aplica-se, também, o disposto nesta lei, segundo Art. $3^{\circ}$ : I - ao pedido de patente ou de registro proveniente do exterior e depositado no País por quem tenha proteção assegurada por tratado ou convenção em vigor no Brasil; e II - aos nacionais ou pessoas domiciliadas em país que assegure aos brasileiros ou pessoas domiciliadas no Brasil a reciprocidade de direitos iguais ou equivalentes (BRASIL, 1996, online).

Em 2004, inaugurou-se a política formal de incentivo à atividade inovativa no Brasil, por meio da Lei $\mathrm{N}^{0} 10.973 / 2004$, chamada Lei de Inovação (BRASIL, 2004). Segundo Araújo et al. (2018), essa lei propõe o apoio e o estímulo ao desenvolvimento social, tecnológico e científico em todo o território nacional, de maneira equilibrada, reconhecendo as desigualdades estruturais entre as diversas regiões do país e procurando incentivar e apoiar a todos aqueles que criarem produtos e processos inovadores, inclusive, nas regiões menos favorecidas.

A lei tem como objetivo estimular a participação do setor privado na inovação. Empresários da área tecnológica e científica poderão beneficiar-se dos incentivos ao desenvolvimento de novos produtos e processos. E, ainda, confere um tratamento especial ao micro e pequeno empresário que investir na atividade inovativa, assegurando a igualdade de oportunidade.

Destaca-se o incentivo à interação ICT-empresa e ao fortalecimento dos agentes intermediadores dessa relação, materializado nas instituições de apoio e os núcleos de inovação tecnológica (NITs). As principais formas de estímulo para promover a interação de instituições e pesquisadores com as empresas são: recebimento de remuneração pela ICT, nos termos de contrato ou convênio, para o compartilhamento ou a permissão para uso de laborató- rios ou instalações, conforme previsto no Art. $4^{\text {o }}$; recebimento de retribuição pecuniária, diretamente da ICT ou da instituição de apoio associada, pelo pesquisador envolvido na prestação de serviço, prevista no Art. $8^{\circ}$, e; recebimento de bolsa de estímulo à inovação, diretamente da instituição de apoio associada à ICT ou de agência de fomento, pelo pesquisador envolvido nas atividades previstas no acordo de parceria firmado com empresas, conforme seu Artigo $9^{\circ}$ (BRASIL, 2004).

Segundo Rauen (2016, p. 22), “o objetivo dessa lei era que tais possibilidades funcionassem como formas efetivas de estímulo ao maior engajamento de ICTs e seus pesquisadores em atividades de inovação com empresas." Porém, durante anos de vigência da Lei de Inovação, esses incentivos foram subutilizados e, de modo geral, as parcerias público-privadas para o desenvolvimento tecnológico permaneceram em patamares aquém dos desejados. Ainda segundo o mesmo autor:

[...] apesar de ter logrado o estabelecimento em regramento jurídico específico de mecanismos de estímulo ao engajamento de entes públicos em atividades de inovação com empresas, a Lei de Inovação não foi suficiente para alterar a dinâmica da pesquisa no Brasil. Universidades públicas e institutos de pesquisa mantêm o padrão de suas formas de produzir conhecimento: estabelecem linhas de pesquisa dissociadas dos interesses do setor produtivo, e produzem como resultados de suas atividades aquilo em que tradicionalmente possuem maior vantagem competitiva: a produção de artigos científicos em periódicos indexados (RAUEN, 2016, p. 22).

Soares et al. (2016) videnciam o papel da lei de inovação e associam a atuação dos NITs ao crescente número de patentes depositados no Brasil, embora ainda se persista o gargalo da transferência de tecnologia. Os autores identificam a necessidade de intensificar a interação entre os atores do sistema por meio de uma estratégia de inovação. 
A efetivação de instrumentos de cooperação ICT-empresa exige tanto mudança de postura dos agentes envolvidos quanto um aprimoramento do poder público em fornecer instrumentos legais que induzam o engajamento das instituições de pesquisa em inovação, o que requer parcerias das ICTs com organizações privadas.

Dessa forma, promulga-se a Ementa Constitucional $\mathrm{N}^{\mathrm{o}} 85$, de fevereiro de 2015, modificando o tratamento das atividades da ciência, tecnologia e inovação, permitindo a criação de instrumentos para a melhor alocação de recursos e contemplando, explicitamente, as organizações privadas como veículos de promoção da inovação. Em 11 de janeiro de 2016, com a promulgação da Lei $\mathrm{N}^{0} 13.243$, popularmente conhecida como Marco Legal de Ciência, Tecnologia e Inovação, buscou-se reduzir os entraves a uma efetiva promoção da inovação.

Essa nova lei avança, segundo Rauen (2016), em diversos pontos na promoção de um ambiente regulatório mais seguro e estimulante para a inovação no Brasil. Entre eles, destacam-se: a formalização das ICTs privadas (entidades privadas sem fins lucrativos) como objeto da lei; a ampliação do papel dos NITs, incluindo a possibilidade de que as fundações de apoio possam ser NITs de ICTs; a diminuição de alguns entraves para a importação de insumos para a pesquisa e o desenvolvimento (P\&D); a formalização das bolsas de estímulo à atividade inovativa, entre outros.

O Marco Legal (BRASIL, 2016) altera e/ou adiciona dispositivos a várias leis pertinentes ao assunto, como a Lei $\mathrm{n}^{\circ} 10.973 / 2004$ (Lei da Inovação); Lei no 8.666/1993 (Lei da Licitação); Lei no 8.958/1994 (Lei que regula as relações entre instituições federais de ensino superior e fundações de apoio).

No que se refere aos pontos relacionados à promoção ICT-empresa, é possível concluir que a nova lei propôs alterações importantes com vistas a reduzir pontos críticos de insegurança jurídica, dando mais clareza à aplicação e à operacionalização da lei, bem como fortalecendo as ferramentas de estímulo à participação de ICTs em atividades de inovação associadas ao segmento produtivo.

\subsection{INSTITUIÇÕES DE CIÊNCIA E TECNOLOGIA (ICTS)}

Segundo a Lei de Inovação $\mathrm{n}^{\mathrm{o}}$ 10.973/2004 (BRASIL, 2004) Art. 2 ${ }^{\circ}$, inciso $\mathrm{V}$, o conceito de ICTs foi estabelecido como "entes da administração pública que executam atividades de pesquisa e inovação, tais como universidades e institutos de pesquisa públicos". Mais tarde, com a nova Lei de Inovação, $n^{\circ} 13.243 / 2016$, esse conceito foi ampliado a outras entidades, como instituições de direito privados sem fins lucrativos, abrangendo e oficializando importantes instituições que já fazem parte do SNI e que produzem pesquisa e geram inovações de grande impacto nacional, como as organizações sociais.

A infraestrutura científica adquire um papel imprescindível, principalmente para os países em desenvolvimento, na qual o sistema nacional de inovação ainda é considerado incompleto dado o estágio de desenvolvimento de suas economias e de suas instituições. Segundo Suzigan, Albuquerque e Cario (2011, p. 9):

Tal infraestrutura, ao gerar conhecimento, atua como instrumento de focalização voltado a identificar as oportunidades tecnológicas a serem aproveitadas pelo país, bem como meio de absorção de conhecimentos ao estabelecer vínculos com a produção científica internacional. Da mesma forma, é um instrumento de apoio ao desenvolvimento industrial por prover conhecimento necessário para o país reestruturar setores produtivos existentes, assim como para desenvolver novos setores produtivos considerados tecnologicamente estratégicos.

Nesse contexto, as Instituições de Ensino Superior, na qualidade de ICTs, assumem um importante papel, representando e ampliando a atuação da administração pública no campo da pesquisa científica e tecnológica. As universidades têm-se direcionado para o empreendedorismo, uma vez que não têm como função única a formação de pessoal qualificado (ensino), 
mas também a função de pesquisa e extensão, em que a universidade coopera com empresas e instituições da sociedade, a fim de proporcionar meios para o desenvolvimento econômico. Essa nova realidade é retratada por Etzkowitz e Zhou (2017, p. 44), que, utilizando a metáfora da tríplice hélice, consideram que "as interações e relacionamentos universidade-indústria-governo fornecem uma metodologia quase ideal para o empreendedorismo e a inovação, movendo a pesquisa/conhecimento para o da prática/uso." Tal interação é possível pela implementação de estruturas híbridas como os escritórios de transferência de tecnologia, que seriam os NITS, e as estruturas como incubadoras.

Não se nega a importância da pesquisa acadêmica na transferência de novos conhecimentos para o mercado, mas acentuam-se os conhecimentos gerados nas universidades como um insumo de importância crescente para os esforços inovativos empresariais. De acordo com os resultados de Ipiranga e Almeida (2012, p. 31), não se pode esquecer-se dos entraves a essa relação cooperativa, advindos da divergência entre os objetivos dessas duas esferas e a inexistência de "arranjos e estruturas específicas - como os escritórios de transferência de tecnologias, as incubadoras e parques tecnológicos - ligadas à Rede e que atuem na interface entre as instituições e organizações de apoio, no sentido de promover o processo de transferência de tecnologia e a consequente geração de inovações."

Para gerenciar a propriedade intelectual nas ICTs e implementar políticas de inovação, a legislação criou os Núcleos de Inovação Tecnológica (NITs), descritos a seguir.

\subsection{O PAPEL DOS NÚCLEOS DE INOVAÇÃO TECNOLÓGICA (NITS)}

A Lei de Inovação de 2004 dispõe sobre $\mathrm{o}$ incentivo à inovação e à pesquisa científica $\mathrm{e}$ tecnológica no ambiente produtivo com a finalidade de promover a capacitação e o alcance da autonomia tecnológica para o desenvolvi- mento industrial do Brasil com a participação das ICTs no processo inovação, exigiu-se a criação dos Núcleos de Inovação Tecnológica - NIT dentro dos Institutos de Ciência e Tecnologia - ICTs, que teriam a função, segundo Martins (2012), de propor, acompanhar e avaliar as políticas de inovação, para promover a proteção e a manutenção da propriedade intelectual e para transferir novas tecnologias para o setor industrial.

As competências básicas dos NIT conforme o art. 16 da Lei de inovação de 2004, são:

Desenvolver estudos de prospecção
tecnológica e de inteligência competi-
tiva no campo da propriedade intelec-
tual, de forma a orientar as ações de
inovação da ICT; Desenvolver estu-
dos e estratégias para a transferência
de inovação gerada pela ICT;
Promover e acompanhar o relacio-
namento da ICT com empresas, em
especial para atividades previstas
nos arts. $6^{\circ}$ a $9^{\text {o }}$; Negociar e gerir os
acordos de transferência e tecnologia
oriundos da ICT (BRASIL, 2004, on-
line).

A lei permite aumentar o número de depósitos nacionais e internacionais das propriedades intelectuais, assim como aumentar a interação universidade-empresa indicado pelo aumento de transferências de tecnologia, maior interação entre ICTs, promovendo a difusão de boas práticas utilizadas na gestão dos NITs mais estruturados. Porém, segundo Martins (2012), também foi possível identificar alguns obstáculos como dificuldade de contratação de especialistas em suas diversas áreas para atuar, exclusivamente, nos NITs; a permanência dos bolsistas por, no máximo, 24 meses, gerando insegurança e perda do pessoal treinado; a necessidade de capacitação do pessoal dos NITs e de pesquisadores no uso da propriedade intelectual e gestão dos ativo intangíveis, especialmente em buscas de anterioridade e redação de patentes; e, finalmente, um maior conhecimento e aplicação das potencialidades da Lei de Inovação. 
Mais tarde, com o Marco Legal da Inovação, o art. 16 da Lei de 2004 foi transformado, ampliando o elenco de competências do NIT, com acréscimos de mais quatro incisos, e acrescentou os parágrafos $2^{\circ}$ a $5^{\circ}$ :

$\S 2^{\circ}$ A representação da ICT pública, no âmbito de sua política de inovação, poderá ser delegada ao gestor do Núcleo de Inovação Tecnológica. $\S 3^{\circ}$ O Núcleo de Inovação Tecnológica poderá ser constituído com personalidade jurídica própria, como entidade privada sem fins lucrativos. $\S 4^{\circ}$ Caso o Núcleo de Inovação Tecnológica seja constituído como personalidade jurídica própria, a ICT deverá estabelecer as diretrizes de gestão e as formas de repasses de recursos. $\S 5^{\circ}$ Na hipótese do $\S 3^{\circ}$, a ICT pública é autorizada a estabelecer parceria com entidades privadas sem fins lucrativos já existentes, para a finalidade prevista no caput (BRASIL, 2004, online).

Segundo Araújo et al. (2018), o aumento da competência dos NITs tinha como objetivo buscar novas parcerias e negócios. A nova lei apresenta as expressões "prospecção tecnológica" e "inteligência competitiva" como conceitos que devem conduzir e facilitar a realização das novas atribuições desses núcleos.

Mayerhoff (2008) ensina:

Estudos de Prospecção constituem a ferramenta básica para a fundamentação nos processos de tomada de decisões em diversos níveis da sociedade moderna. O propósito dos estudos de prospecção não é desvendar o futuro, mas, sim, delinear e testar visões possíveis e desejáveis para que sejam feitas, hoje, escolhas que contribuirão, da forma mais positiva possível, na construção do futuro. Tais visões podem ajudar a gerar políticas de longo termo, estratégias e planos que dispõem circunstâncias futuras prováveis e desejadas em um estreito alinhamento. (MAYERHOFF, 2008, p. 7).
Já Teixeira e Souza (2013, online), defendem que a inteligência competitiva consiste na "análise das informações sobre o mercado e da geração das recomendações para os decisores dentro das empresas." Para Marinho e Corrêa (2016):

Percebe-se, portanto, que ambas as atividades devem realmente ser tratadas como complementares e, no âmbito das ICTs, podem ajudar na antevisão às futuras tendências tecnológicas e a buscar o melhor parceiro para a concepção, o desenvolvimento e/ou produção das inovações pesquisadas no ambiente acadêmico. Nesse contexto, cresce de importância a atuação dos NITs como elemento legal e institucional a impulsionar as atividades das ICTs na definição das estratégias que melhor atendam às suas particularidades (MARINHO; CORREAA, 2016, p. 254).

Portanto, conclui-se que, embora a Lei de Inovação de 2004 já estipulasse a obrigatoriedade da implantação de NITs para gerir a atividade de inovação nas ICTs, foi a nova Lei de Inovação de 2016 que ampliou as competência legais do NIT, fortalecendo-o como órgão capaz de estabelecer e intermediar a comunicação entre a academia e as empresas. Dessa maneira, conforme Araújo et al. (2018), o setor deve-se tornar um apoio eficaz aos pesquisadores, tanto na obtenção da proteção dos resultados das pesquisas, quanto na efetivação de novas parcerias e na transferência da tecnologia criada na academia para benefício da sociedade.

\section{METODOLOGIA}

O presente artigo utilizou-se da pesquisa descritiva que, segundo Cervo e Bervian (2002, p. 66), "observa, registra, analisa e correlaciona fatos ou fenômenos (variáveis) sem manipulá-los", ela "procura descobrir, com a precisão possível, a frequência com que um fenômeno ocorre, sua relação e conexão com outros, sua natureza e características". 
Entre as formas de pesquisa descritiva, tem-se a pesquisa documental, em que "são investigados documentos a fim de se poder descrever e comparar usos e costumes, tendências, diferenças e outras características. Estuda a realidade presente, e não o passado, como ocorre com a pesquisa histórica." (CERVO; BERVIAN, 2002, p. 67). Além dos dados escritos, os documentos podem ser formados por objetos, elementos iconográficos, imagens, vídeos ou material virtual. "Todos os documentos referidos constituem a base da observação documental. Esta pode ser definida como a observação que tem como objeto não os fenômenos sociais, quando e como se produzem, mas as manifestações que registram esses fenômenos e as ideias elaboradas a partir deles." (RICHARDSON, 2009, p. 228).

Consideraram-se como fonte documental os repositórios de informações das instituições relacionadas às universidades (INPI, Capes. CNPq), dos quais foram obtidos dados que indicam o processo de comprometimento com ações de inovação, evidenciado por meio de indicadores de C\&T e pela existência de uma estrutura de ação, os NITs.

Consultas realizadas ainda em 2018 a instituições como a Associação Nacional de Entidades Promotoras de Empreendimentos Inovadores (Anprotec), ao Fórum Nacional de Gestores de Inovação e Transferência de Tecnologia (Fortec) e a Rede NIT-NE. A consulta a essa instituição revelou que as instituições nordestinas se encontravam, em grande parte, no processo de implementação dos mecanismos previstos na legislação, permitindo uma base mais homogênea para análise.

A pesquisa nas instituições foi realizada no ano de 2019 com o propósito de identificar a implementação da legislação referente à inovação nas universidades. Esse período foi escolhido por ser o ano subsequente à promulgação do Decreto $n^{\circ} 9.283$, de 7 de fevereiro de 2018. Para confronto com os dados coletados na etapa bibliográfica, fez-se uma busca para identificar as universidades federais sediadas no Nordeste. Nesse caso, a amostra é do tipo não probabilística, pois consideraram-se as universidades federais nordestinas, definidas para se obter um contexto geográfico que permita uma melhor percepção da evolução das ICTs no processo de inovação.

A apresentação dos resultados centrou-se na identificação dos elementos elencados pela legislação e em sua identificação nas instituições pesquisadas, assim como os indicadores de atividade geradora de conhecimento e de inovação.

\section{RESULTADOS}

A pesquisa revelou uma crescente mobilização das instituições quanto à implementação dos mecanismos referentes à inovação, previstos em instrumentos legais. Se desde 1996, com a lei de propriedade industrial, o investimento em inovação já havia sido despertado, é em 2004, com a Lei no 10.973, de 2 de dezembro de 2004, as instituições de pesquisa encontram as condições para, realmente, explorarem seu potencial criativo. Especialmente no caso das instituições públicas, a legislação passou a disciplinar o estímulo e a gestão do processo de inovação dentro das instituições e sua relação com o poder público e o ambiente empresarial, seguindo a linha da chamada tríplice-hélice (ETZKOWITZ, LEYDESDORFF; 1997).

Com a nova legislação, as ICTs iniciam o processo de criação de suas estruturas internas, o que ocorre nos anos seguintes. No quadro abaixo, ressalta-se a principal modificação na lei de inovação, que é a publicação do chamado Marco Legal da Ciência \& Tecnologia (BRASIL, 2016), que revisa a Lei de Inovação e dá nova redação a muitos dos artigos originais, atualizando escopo da lei para dar mais celeridade e segurança às decisões envolvendo a gestão da inovação nas instituições. 
Quadro 1 - Mudanças na legislação de inovação

\begin{tabular}{|c|c|c|}
\hline Aspectos & $\begin{array}{c}\text { Lei no10.973/1994 (Lei de } \\
\text { Inovação) }\end{array}$ & Lei 13.243/2016 (Marco Legal) \\
\hline Ambientes Promoção Inovação & Art $3^{\circ}$ & Nova redação \\
\hline Compartilhar Estrutura Pesquisa & Art. $4^{\circ}$ & Nova redação \\
\hline $\begin{array}{c}\text { Relação ICT x poder público e } \\
\text { Mercado }\end{array}$ & $\begin{array}{c}\text { Art } 6^{\circ}, 7^{\circ}, 8^{\circ}, 9^{\circ}, 10^{\circ} \text { e } 11^{\circ} \\
\text { Direitos do Criador }\end{array} 1^{\circ}, 14^{\circ}, 15^{\circ}$ & Nova redação \\
\hline NIT & $16^{\circ}$ & Nova redação \\
\hline Inovação nas empresas & $19^{\circ}$ & Nova redação \\
\hline Contratação direta & Art $20^{\circ}$ & Nova redação \\
\hline Incentivo Inventor independente & Art $22^{\circ}$ & Nova redação \\
\hline
\end{tabular}

Fonte: elaboração própria.

Percebe-se que muitos dos artigos da lei de inovação (BRASIL, 2004) tiveram uma nova redação, alterando, significativamente, o alcance e a segurança para as instituições em não apenas desenvolverem projetos científicos e tecnológicos, mas em levarem-no efetivamente ao mercado.

Nesse processo, destaca-se a criação do NIT, responsável por planejar e gerir o processo de proteção e transferência dos resultados de pesquisa, bem como estimular o potencial inovador e empreendedor nas instituições. Passa, assim, a desfrutar, em 2016, de uma maior autonomia para ação, conforme foi citado anteriormente neste mesmo artigo.

O destaque fica pela possibilidade de se constituir um NIT com personalidade jurídica própria, ou seja, com certa autonomia para operacionalizar as diretrizes da política de inovação das instituições.

Porém, a maior parte dos órgãos responsáveis pela inovação é vinculada à Pró-Reitoria de Pesquisa, seja na forma de núcleo ou de coordenação. A maioria possui espaço próprio dentro do endereço eletrônico da universidade, descrevendo as atividades que desempenham, sendo as mais comuns a proteção intelectual (patentes, marcas, indicações geográficas e registro de software) e normas para transferência de tecnologia.

No quadro a seguir, apresenta-se a estrutura dos órgãos responsáveis pela inovação nas universidades federais.

Quadro 2 - Órgãos responsáveis pela inovação nas IES Federais

\begin{tabular}{|c|c|c|c|c|}
\hline $\mathbf{U F}$ & ICT & $\begin{array}{l}\text { Legislação } \\
\text { Interna }\end{array}$ & $\begin{array}{l}\text { NIT ou equivalente } \\
\text { (Documento Preferível) }\end{array}$ & Endereço Eletrônico \\
\hline $\mathrm{AL}$ & UFAL & $\begin{array}{c}\text { Resolução } \\
\text { Consuni } \\
015 / 2008 \\
\text { Criação do NIT }\end{array}$ & NIT & $\begin{array}{c}\text { https://ufal.br/ufal/pesquisa-e-inovacao/ } \\
\text { inovacao-tecnologica }\end{array}$ \\
\hline BA & UFBA & $\begin{array}{c}\text { Regimento da } \\
\text { Universidade } \\
\text { (2013) }\end{array}$ & $\begin{array}{l}\text { Coordenadoria de } \\
\text { Criação e Inovação }\end{array}$ & https://nit.ufba.br/ \\
\hline BA & UFOB & $\begin{array}{c}\text { Em } \\
\text { elaboração }\end{array}$ & $\begin{array}{l}\text { Coordenadoria de } \\
\text { Criação e Inovação }\end{array}$ & $\begin{array}{l}\text { https://propgpi.ufob.edu.br/index.php/ } \\
\text { inovacao }\end{array}$ \\
\hline BA & UFRB & $\begin{array}{l}\text { Em } \\
\text { elaboração }\end{array}$ & $\begin{array}{l}\text { Coordenação de Criação } \\
\text { e Inovação (CINOVA) / } \\
\text { Pró-Reitoria de Pesquisa, } \\
\text { Pós-Graduação, Criação e } \\
\text { Inovação (PPGCI) }\end{array}$ & $\begin{array}{c}\text { https://www.ufrb.edu.br/ppgci/cinova/ } \\
\text { apresentacao }\end{array}$ \\
\hline
\end{tabular}




\begin{tabular}{|c|c|c|c|c|}
\hline $\mathrm{CE}$ & UFC & $\begin{array}{l}\text { Resolução } \\
\text { CONSUNI } \\
38 / 2017\end{array}$ & $\begin{array}{c}\text { Coordenadoria de } \\
\text { Inovação Tecnológica da } \\
\text { Universidade Federal do } \\
\text { Ceará (UFC Inova) }\end{array}$ & http://www.cit.ufc.br/pt/ \\
\hline $\mathrm{CE}$ & UFCA & $\begin{array}{l}\text { Resolução } \\
\text { Consuni }^{\circ} \\
04 / 2019\end{array}$ & NIT & Sem Endereço Eletrônico \\
\hline MA & UFMA & $\begin{array}{l}\text { Resolução } \\
\text { Consuni no } \\
153 / 2010\end{array}$ & $\begin{array}{l}\text { Departamento de Apoio } \\
\text { a Projetos de Inovação } \\
\text { e Gestão de Serviços } \\
\text { Tecnológicos (DAPI) }\end{array}$ & $\begin{array}{l}\text { http://portais.ufma.br/PortalProReitoria/ } \\
\text { pppgi/paginas/pagina_estatica.jsf?id= } 88\end{array}$ \\
\hline PB & UFPB & $\begin{array}{c}\text { Resolução } \\
\text { n}^{\circ} 15 / 2006 \\
\text { do Conselho } \\
\text { Universitário. } \\
\text { Resolução } \\
\text { Conselho } \\
\text { Universitário } \\
\text { No 18/2017 }\end{array}$ & $\begin{array}{c}\text { Agência UFPB de } \\
\text { Inovação Tecnológica } \\
\text { - INOVA. (Vinculado a } \\
\text { Reitoria) - }\end{array}$ & $\begin{array}{c}\text { http://www.ufpb.br/inova/contents/menu/ } \\
\text { conheca-a-inova }\end{array}$ \\
\hline PB & UFCG & $\begin{array}{l}\text { Resolução } \\
\text { Colegiado } \\
\text { Pleno N } \\
13 / 2010\end{array}$ & $\begin{array}{l}\text { Núcleo de Inovação } \\
\text { e Transferência de } \\
\text { Tecnologia - NITT }\end{array}$ & http://www.nitt.ufcg.edu.br/ \\
\hline PE & UFPE & $\begin{array}{c}\text { Resolução } \\
\text { 02/2019 - } \\
\text { Conselho } \\
\text { Universitário }\end{array}$ & $\begin{array}{l}\text { Diretoria de Inovação - } \\
\text { POSITIVA }\end{array}$ & https://www.ufpe.br/positiva \\
\hline PE & UFRPE & $\begin{array}{l}\text { Resolução } \\
\text { CEPE N }^{\circ} \\
456 / 2008\end{array}$ & NIT & http://www.nit.ufrpe.br/ \\
\hline PE & UNIVASF & $\begin{array}{c}\text { Resolução } \\
11 / 2018 \\
\text {-Conselho } \\
\text { Universitário }\end{array}$ & $\begin{array}{c}\text { NIT-Univasf/Pró - } \\
\text { Reitoria de Pesquisa, } \\
\text { Pós - Graduação e } \\
\text { Inovação }\end{array}$ & https://nitunivasf.wixsite.com/nitunivasf \\
\hline PI & UFPI & $\begin{array}{c}\text { Resolução } \\
\text { 036/2008 } \\
\text { Conselho } \\
\text { Universitário }\end{array}$ & Nintec & https://www.ufpi.br/nintec \\
\hline $\mathrm{RN}$ & UFRN & $\begin{array}{l}\text { Diversas } \\
\text { Resoluções } \\
\text { Internas }\end{array}$ & $\begin{array}{l}\text { Núcleo de Inovação } \\
\text { Tecnológica e } \\
\text { Empreendedorismo(Resolução } \\
\text { Consuni nan 004/2007) }\end{array}$ & http://www.nit.ufrn.br/ \\
\hline $\mathrm{RN}$ & UFERSA & $\begin{array}{l}\text { Resolução } \\
\text { Consuni/ } \\
\text { UFERSA No } \\
\text { 006/2012. }\end{array}$ & $\begin{array}{l}\text { NIT-UFERSA/Pró- } \\
\text { reitoria de Pesquisa e } \\
\text { Pós-graduação-PROPPG } \\
\text { (Resolução Consuni/ } \\
\text { UFERSA No 005/2014) }\end{array}$ & https://nit.ufersa.edu.br/ \\
\hline SE & UFS & $\begin{array}{l}\text { Portaria No } \\
938 / 2005\end{array}$ & $\begin{array}{c}\text { Coordenação de } \\
\text { Inovação e Transferência } \\
\text { de Tecnologia - } \\
\text { CINTTEC }\end{array}$ & http://cinttec.ufs.br/pagina/2167 \\
\hline
\end{tabular}

Fonte: dados da pesquisa. 
No quadro 2, é possível constatar que na UFPB e UFPI, os NITs são vinculados às reitorias e, na UFPE, funciona como uma diretoria. Nas demais instituições, em que se obtiveram informações, os NITs foram criados como coordenação vinculada à Pró-reitoria de Pesquisa.

As instituições que aparecem com legislação ou NIT em elaboração são aquelas criadas recentemente como reflexo da expansão das instituições de educação superior. No geral, os NITs foram criados nos anos posteriores a Lei de Inovação (BRASIL, 2004).

As mudanças recentes são fruto do Marco legal de 2016 e do Decreto $\mathrm{N}^{\circ}$ 9.283 , de 7 de fevereiro de 2018 , que a regulamenta. Por ser um imperativo legal, a criação de um órgão para gerir a inovação das universidades não apresenta novidade, chamando atenção à sua pouca estruturação. Muitos deles, apesar de criados há mais de 10 anos, apresentam apenas informações básicas sobre os serviços do NIT, reproduzindo instruções de terceiros, como o INPI. São poucas unidades que disponibilizam instrumentos e orientações específicas sobre como um interessado deve proceder.

Por ser um órgão que visa integrar a pesquisa acadêmica e as demandas de mercado, esperava-se uma maior gama de ações nas páginas dos núcleos. As dificuldades em promover a inovação e o empreendedorismo nas instituições revelam-se ainda resistentes, em um cenário em que a publicação de artigos ainda possui maior importância do que o depósito de patentes ou a transferência de tecnologia.

No quadro a seguir, realizou-se uma análise sobre o número de programas de doutorados das IES federais do NE que possuem nota 6 ou 7, considerados excelentes segundo critérios da Coordenação de Aperfeiçoamento de Pessoal de Nível Superior - CAPES.
Quadro 3 - IES federais que possuem programas de doutorado com notas 6 ou 7

\begin{tabular}{|c|c|c|}
\hline UF & ICT & $\begin{array}{c}\text { Número de Programas de } \\
\text { Doutorados com nota 6ou 7 }\end{array}$ \\
\hline BA & UFBA & 5 \\
\hline CE & UFC & 10 \\
\hline MA & UFMA & 1 \\
\hline PB & UFPB-JP & 2 \\
\hline PB & UFCG & 1 \\
\hline PE & UFPE & 9 \\
\hline PE & UFRPE & 2 \\
\hline RN & UFRN & 3 \\
\hline RN & UFERSA & 1 \\
\hline
\end{tabular}

Fonte: elaboração própria.

O quadro 3 demonstra que, das 16 (dezesseis) universidades federais existentes no Nordeste, apenas 9 (nove) delas possuem programas de doutorado com notas 6 e 7. Segundo a portaria Capes, de $\mathrm{n}^{0} 59$, de 21 de março de 2017, sobre o regulamento da avaliação trienal, podem obter notas 6 e 7 os programas com Doutorado com nota 5 e conceito muito bom em todos os quesitos da ficha de avaliação, que possuam, entre outros fatores, "Desempenho equivalente ao dos centros internacionais de excelência na área" e "Nível de desempenho diferenciado em relação aos demais programas da área no que se refere à formação de doutores e à produção intelectual." (CAPES, 2017, p. 7).

A nota de um programa de pós-graduação por si só não pode ser considerado como um indicador relevante de explicação para o número de patente ou atividade inovadora nas universidades. Os critérios de excelência que os programas 6 e 7 precisam alcançar exigem um desempenho em todos os critérios, o que inclui o depósito de patentes. Da mesma forma, se a produção intelectual alcança altos padrões de qualidade, torna-se mais provável a produção de conhecimento patenteável, e, como a obtenção desses conceitos requer inserção internacional, pode-se sugerir uma hipótese de que essa excelência se transforme em patentes. Porém, as linhas de estudo atuais associam 
mais o depósito de patentes com a área de conhecimento do que com o grau de excelência dos programas existentes. Esse é o caso do estudo de Chaym et al. (2018), que relatam 433 patentes em 503 teses de doutorado defendidas. Uma comparação entre os quadros 3 e 4 mostram que as instituições com programas 6 e 7 destacam-se no número de patentes. É uma análise que precisaria de múltiplos fatores explicativos, mas poderia ser um indicativo de que a busca por excelência gera resultados condizentes com os requisitos de patenteabilidade?

Um dos indicadores de gestão dos NITs refere-se ao número de pedidos de patenteamento e aos registros efetivamente concedidos. Segundo Martins (2012), trata-se de um indicador capaz de revelar tanto o nível de produção de pesquisas realizadas pelas ICTs, quanto a capacidade dos NITs em acompanhar, mapear e identificar essas atividades, e, até mesmo, de atuar como articuladores entre áreas e departamentos. Na tabela abaixo, pode-se verificar o número de patentes requeridas pelas universidades federais do Nordeste.

Quadro 4 - Número de Patentes requeridas por Instituição

\begin{tabular}{|c|c|c|}
\hline UF & ICT & $\mathbf{N}^{\mathbf{0}}$ Patentes Requeridas \\
\hline $\mathrm{AL}$ & UFAL & 127 \\
\hline $\mathrm{BA}$ & UFBA & 220 \\
\hline $\mathrm{BA}$ & UFOB & 9 \\
\hline $\mathrm{BA}$ & UFRB & 43 \\
\hline $\mathrm{CE}$ & UFC & 314 \\
\hline $\mathrm{CE}$ & UFCA & 0 \\
\hline $\mathrm{MA}$ & UFMA & 151 \\
\hline PB & UFPB & 410 \\
\hline PB & UFCG & 258 \\
\hline PE & UFPE & 370 \\
\hline PE & UFRPE & 138 \\
\hline PE & UNIVASF & 61 \\
\hline PI & UFPI & 114 \\
\hline RN & UFRN & 238 \\
\hline RN & UFERSA & 0 \\
\hline SE & UFS & 218 \\
\hline
\end{tabular}

Fonte: elaboração própria.
As Instituições possuem um bom número de patentes requeridas, especialmente após a publicação da Lei de Inovação no ano de 2004. Grande parte do quantitativo representado no quadro 4 ocorreu a partir de 2005 , concomitante com a criação e a evolução dos NITs nas instituições e sob o efeito da lei de inovação. Considerado a existência de uma lei de propriedade industrial desde 1996, esses dados podem indicar a importância estratégica dos Núcleos para as Universidades, em que a questão da propriedade intelectual, bem como do licenciamento de tecnologia, pode ser potencializada pela existência de um órgão especializado.

No caso das instituições que aparecem com nenhuma patente ou poucas patentes, elas foram criadas recentemente e ainda estão desenvolvendo seus mecanismos de proteção da PI e estimulo à inovação. Até então, as patentes foram depositadas pela instituição da qual foram originadas.

Veem-se registrando um incremento no depósito de patentes após a publicação da Lei de Inovação, mas sem o mesmo desempenho na transferência das tecnologias, como denota Soares et al. (2016). Castro e Souza (2012) denotam a pouca autonomia dos NITs nas universidades brasileiras, uma vez que os acordos realizados entre universidade-empresa devem ser autorizados pela Reitoria ou pelos conselhos universitários. Ficando, assim, subordinados a uma política mais rígida e burocrática de acordos e contratos.

Também é possível constatar, por meio dos dados contidos no quadro 4 , e segundo notícias dos próprios portais das universidades, que as instituições que possuem maior número de patentes são as que vêm desempenhando papel ativo no que se refere à gestão da produção de inovação nas universidades, além de possuírem uma ação ampliada dos NITs, tanto em nível de estruturação quanto de institucionalização.

Os dados apresentados mostram um crescente envolvimento das universidades nordestinas com a proteção intelectual, evidenciado tanto pelo número de patentes como pela busca por excelência acadêmica evidenciada 
na obtenção de cursos de pós-graduação com nota 6 e 7. A própria mudança da legislação ressalta um reconhecimento dessas instituições em avançarem para além do depósito de patentes, pois, sem uma política clara de inovação, as patentes tendem a ficar nas prateleiras das universidades.

Como os dados demonstram, mesmo com dificuldades, essas instituições conseguiram implementar seus NITs, e estes desempenham um importante papel na proteção da produção intelectual de suas instituições. Contudo, como expõe Martins (2012), há necessidade de uma maior sensibilização dentro das próprias ICTs, de modo a convencer os dirigentes e a comunidade acadêmica sobre a importância do NIT, além de reforçar a necessidade de ações governamentais de divulgação e de indução para o estabelecimento desses Núcleos nas instituições. Também se trata da falta ou pouca institucionalização dos NITs e das políticas instáveis das gestões nas universitárias.

\section{CONCLUSÃO}

No presente artigo, foi possível identificar o processo de institucionalização da Lei de Inovação da região Nordeste do Brasil, mas precisamente nas universidades federais do NE, na qual se identificou a implantação dos Núcleos de Inovação Tecnológicas (NITs) em sua estrutura como uma unidade formal relacionada à inovação, fosse um NIT ou um órgão com suas funções. Apesar de cumprirem a obrigatoriedade legal, muitas não desenvolvem ações próprias de promoção da inovação, limitando-se a reproduzir informações de entidades externas, como o INPI ou o Fortec.

As alterações registradas na legislação pelo Marco Legal evidenciam as limitações que essas entidades estavam sofrendo. Considerando que o número de patentes cresceu, a necessidade de nova redação à Lei de Inovação evidencia dificuldades em outros elementos da política de inovação. A transposição de dispositivos legais para rotinas organizacionais foi pouco identificada nos núcleos, resultando em uma ação ainda limitada aos aspectos externos provenientes de instituições com normas e práticas mais consolidadas, como o INPI.

Faz-se necessária uma ação ordenada de institucionalização desses núcleos por meio de uma definição clara das diretrizes, dos princípios e das políticas dos NITs em cada universidade, assim como também de mecanismos que garantam uma maior estabilidade da equipe técnica desses núcleos.

Também é importante que as academias considerem as ações desses núcleos como parte de uma política estratégica de inovação das instituições, o que garantirá o desenvolvimento e a competitividade, assim como também a indução e a valorização dos trabalhos dos pesquisadores e do papel das universidades. Porém, devido a os Núcleos de Inovação serem ainda recentes, suas funções estratégicas ainda estão em fase de construção. Castro e Souza (2012) afirmam que uma das razões para essa situação é o fato de que seus esforços ainda estão voltados para a legitimação do seu papel. Embora gargalo ainda persista, começa-se a ver evolução no papel da universidade no depósito de patentes, o que pode ser considerado como um fruto da criação dos mecanismos de promoção da inovação, como os NITs (BUAINAIN; SOUZA, 2018).

Quantos às limitações, pelo fato de muitas das instituições ainda estarem implementando sua política de inovação, não se buscou uma coleta de dados em documentos das próprias universidades. Isso poderia criar um viés pela indisponibilidade de informações. Embora se identifiquem ações e instrumentos orientadores para uma ação inovadora, ainda são muito heterogêneos para permitirem uma análise consistente. Outra limitação é a não utilização de dados primários, obtidos de fontes dos próprios NITs, que forneceriam um panorama mais realista da evolução e dos gargalos na atuação desses órgãos.

Como sugestão de pesquisa futura, evidencia-se a necessidade de coleta de informações in loco, via pesquisa de campo, sobre o planejamento e a gestão dos NITs, especial- 
mente sob o impacto do Marco Legal e do Decreto $\mathrm{N}^{\circ} 9.283 / 2018$ e a ampliação do uso de dados documentais advindos da oficialização da política de inovação e dos relatórios de gestão das universidades.

\section{REFERÊNCIAS}

ARAÚJO, Nizete Lacerda et al. Marco Legal da Inovação. Rio de Janeiro: Lumen Juris, 2018.

BARBOSA, D. B. Uma Introdução à Propriedade Intelectual. Rio de Janeiro: Lumen Juris, 2003.

BRASIL. Lei $\mathrm{n}^{\circ}$ 9.279, de 14 de maio de 1996. Regula direitos e obrigações relativos à propriedade industrial. Brasília, DF: Presidência da República, 1996. Disponível em: http:// www.planalto.gov.br/ccivil_03/leis/19279.htm. Acesso em dezembro de 2019.

BRASIL. Lei $\mathbf{n}^{\mathbf{0}} \mathbf{1 0 . 9 7 3}$, de 2 de dezembro de 2004. Dispõe sobre incentivos à inovação e à pesquisa científica e tecnológica no ambiente produtivo e dá outras providências. Brasília, DF: Presidência da República, 2004. Disponível em: https://www.planalto.gov.br/ccivil_03/Ato2004-2006/2004/Lei/L10.973.htm. Acesso em 5 dez. 2019.

BRASIL. Lei $n^{\circ} \mathbf{1 3 . 2 4 3}$, de 11 de janeiro de 2016. Dispõe sobre estímulos ao desenvolvimento científico, à pesquisa, à capacitação científica e tecnológica e à inovação [...].Brasília, DF: Presidência da República, 2016. Disponível em: http://www.planalto.gov.br/ ccivil_03/_ato2015-2018/2016/lei/113243.htm. Acesso em: 9 dez. 2019.

BUAINAIN, Antônio Márcio; SOUZA, Roney Fraga. Propriedade intelectual, inovação e desenvolvimento: desafios para o Brasil. Rio de Janeiro: ABPI, 2018.

CAPES. Portaria n. 57, de 21 de março de
2017. Dispõe sobre o regulamento da Avaliação Quadrienal. Brasília, 2017. Disponível em: https://docs.google.com/viewer?a=v\&pid=sites\&srcid=Y2FwZXMuZ292LmJyfGF2YWxpYWNhby1xdWFkcmllbmFsfGd4OjY0NTMxNTImMWE1MGY4NTc. Acesso em: 8 dez. 2019.

CASTRO, B.; SOUZA, G. O papel dos Núcleos de Inovação Tecnológica (NITS) nas universidades brasileiras. Line em Revista, Rio de Janeiro, v. 8, n. 1, mar. 2012. Disponível em: http://www.ibict.br/liine. Acesso em: $7 \mathrm{dez}$. 2019.

CERVO, Amado L.; BERVIAN, Pedro A. Metodologia cientifica. 5. ed. São Paulo: Pearson Prentice Hall, 2002.

CHAYM, Carlos Dias et al. Produção de Conhecimento em Ciência, Tecnologia \& Inovação: uma avaliação dos Doutores formados pela Rede Nordeste de Biotecnologia. Revista Gestão em Análise, Fortaleza, v. 7, n. 2, p. 133-150, dez. 2018. Disponível em: https:// periodicos.unichristus.edu.br/gestao/article/ view/2012. Acesso em: 8 dez. 2020. doi:http:// dx.doi.org/10.12662/2359-618xregea.v7i2. p133-150.2018.

CNI - Confederação Nacional da Indústria. Competitividade Brasil 2019-2020. Brasília: CNI, 2020

DRUCKER, P. F. Inovação e espírito empreendedor: práticas e princípios. 2. ed. São Paulo: Pioneira, 1987.

ETZKOWITZ, H.; LEYDESDORFF, L. Universities in the Global Knowledge Economy: A Triple Helix of Academic-Industry-Government Relations. Londres: Cassell, 1997.

ETZKOWITZ, Henry; ZHOU, Chunyan. Hélice tríplice: inovação e empreendedorismo universidade-indústria-governo. Estudos Avançados, v. 31, n. 90, 2017. 
IPIRANGA, Ana Silvia Rocha ; ALMEIDA, Priscilla Corrêa da Hora . O tipo de pesquisa e a cooperação universidade, empresa e governo: uma análise na rede nordeste de biotecnologia. Organizações \& Sociedade (Online), v. 19, p. 17-34, 2012.

KLEBIS, Daniela. Inovação e empreendedorismo são exigência para ICTs. Agência de notícias da Confap, 2 maio 2016. Disponível em: http://confap.org.br/news/inovacao-e-empreendedorismo-sao-exigencias-para-icts/. Acesso em: 1 abr. 2018.

MACHADO, H. P. Vier; SARTORI, Rejane; CRUBELLATE, J. Marcelo. Institucionalização de núcleos de inovação tecnológica em Instituições de ciência e tecnologia da região sul do Brasil. Revista Eletrônica de Administração - REAd, Porto Alegre, v. 23, n. 3, p. 5-31, set./ dez. 2017. Disponível em: http:// www.scielo.br/pdf/read/v23n3/1413-2311-read-23-3-5.pdf . Acesso em: 5 abr. 2018.

MARINHO, Bruno C.; CORRÊA, Lenilton D.P. Novo Marco da Inovação no Brasil: breve análise dos reflexos das alterações da Lei $\mathrm{n}^{\circ}$ 10.973/2004 para os Núcleos de Inovação Tecnológica. Revista de Direito, Inovação, Propriedade Intelectual e Concorrência, v. 2, n. 1, jan./jun. 2016. Disponível em: https://www. indexlaw.org/index.php/revistadipic/article/ download/918/912. Acesso em: 5 dez. 2019.

MARTINS, Rubens. Os Núcleos de Inovação Tecnológica como estratégia das políticas de inovação do MCT. Latin American Journal of Business Management, Taubaté, v. 3, n. 2, jul./dez. 2012. Disponível em: https:// www.lajbm.com.br/index.php/journal/article/ view/95/60. Acesso em: 5 dez. 2019.

MAYERHOFF, Zea Duque V. L. Uma análise sobre os Estudos de Prospecção Tecnológica. 2008. Disponível em: https://portalseer.ufba. br/index.php/nit/article/viewFile/3538/2637. Acesso em: 5 dez. 2019.
RAUEN, Cristiane Vianna. O Novo Marco Legal da Inovação no Brasil: o que muda a relação ICT-EMPRESA?. Radar, Rio de Janeiro, v. 43, p. 22-35, fev. 2016. Disponível em: http:// www.ipea.gov.br/portal/images/stories/PDFs/ radar/160309_radar43_cap_3.pdf. Acesso em: 7 dez. 2019.

REDE ICT. Instituições de Ciência e Tecnologia (ICTs). Disponivel em: http://www.redetic. rnp.br/redetic/instituicoes-de-ciencia-e-tecnologia-icts/. Acesso em: 14 out. 2019.

SOARES, Thiago J. C. C. et al. O sistema de inovação brasileiro: uma análise crítica e reflexões. Interciência, v. 41, n. 10, out./2016.

SUZIGAN, Wilson; ALBURQUERQUE, Eduardo da Motta e; CARIO, Silvio Antônio Ferraz. Em busca da inovação: interação universidade-empresa no Brasil. Belo Horizonte: Autêntica, 2011.

TEIXEIRA, Renata C.; SOUZA, Renato R. O uso das Informações Contidas em Documentos de Patentes nas práticas de Inteligência Competitiva: apresentação de um estudo das patentes da UFMG. Perspectiva em Ciência da Informação, v. 18, n. 1, jan./mar. 2013. Disponível em: http://www.scielo.br/pdf/pci/v18n1/08. pdf. Acesso em: 3 dez. 2019. 